\title{
Inclusion-Interaction Assembly Strategy for Constructing pH/Redox Responsive Micelles for Controlled Release of 6-Mercaptopurine
}

\author{
Mingyuan Tan*, Hua Zheng, Xueqiong Zhang*, Zhiyan Yu, Zhao Ye, Liyan Shi, Kaikai Ding \\ Department of Pharmaceutical Engineering, School of Chemistry, Chemical Engineering and Life Sciences, \\ Wuhan University of Technology, Wuhan, China \\ Email: ${ }^{*}$ tanmingyuan@qq.com, 3 365464583@qq.com
}

Received 15 May 2015; accepted 5 July 2015; published 8 July 2015

Copyright $@ 2015$ by authors and Scientific Research Publishing Inc.

This work is licensed under the Creative Commons Attribution International License (CC BY). http://creativecommons.org/licenses/by/4.0/

(c) (i) Open Access

\section{Abstract}

An inclusion-interaction assembly strategy was used to construct novel $\mathrm{pH} / \mathrm{redox}$ responsive core-shell micelles with hydrophobic drug as the core and hydrophilic polymer as the shell. At first, a dimer of hydrophobic drug 6-mercaptopurine and a hydrophilic $\beta$-CD grafted carboxymethyl chitosan were synthesized. Then, a novel amphiphilic inclusion complex was prepared with the dimer being partially embedded into the cavity of $\beta$-CD moiety. It self-assembled into $\mathrm{pH} / \mathrm{redox}$ responsive core-shell micelles in distilled water. TEM confirmed that the micelles possessed a spherical core-shell configuration with a mean size of about $160 \mathrm{~nm}$. DLS showed that the micelles were stable in aqueous solution. Their particle diameters altered with $\mathrm{pH}$ values as well as glutathione (GSH) concentrations and respectively attained a maximum value at pH 6.0 and $20 \mathrm{mM}$ GSH. Release profiles of 6-mercaptopurine showed a low release rate (about $27 \mathrm{wt} \%$ after $48 \mathrm{~h}$ ) in pH 7.4 medium with $10 \mu \mathrm{M} \mathrm{GSH}$, and a marked increase (over $88 \mathrm{wt} \%$ after $48 \mathrm{~h}$ ) in pH 5.0 medium with $20 \mathrm{mM} \mathrm{GSH}$. In vitro cytotoxicity test showed that the micelles had a dose-dependent toxicity for HeLa cells, indicating a great potential for controlled release of 6-mercaptopurine in tumor cells.

\section{Keywords}

Chitosan, Cyclodextrin, 6-Mercaptopurine, pH-Sensitive, Redox-Responsive, Controlled Release

\section{Introduction}

$\beta$-Cyclodextrin $(\beta$-CD) is a natural cyclic oligosaccharide composed of 7 glucose units linked by $\alpha-1,4$ glyco-

"Corresponding authors.

How to cite this paper: Tan, M.Y., Zheng, H., Zhang, X.Q., Yu, Z.Y., Ye, Z., Shi, L.Y. and Ding, K.K. (2015) Inclusion-Interaction Assembly Strategy for Constructing pH/Redox Responsive Micelles for Controlled Release of 6-Mercaptopurine. Materials Sciences and Applications, 6, 605-616. http://dx.doi.org/10.4236/msa.2015.67063 
sidic bonds, with a hydrophilic outer surface and a hydrophobic inner cavity [1]-[3]. Due to inclusion interactions, a wide range of hydrophobic drugs can be embedded into the hydrophobic cavities to form inclusion complexes, thus significantly increasing the solubility and permeability of the drugs [4]. Moreover, grafting $\beta$-CD onto polymers can result in materials with unique features and excellent biocompatibility [5]. A lot of $\beta$-CD containing polymers have been prepared and utilized to build supramolecular systems [6].

In recent years, our group has prepared a variety of polymeric micelles, in which cores and shells are linked by covalent bonds [7]-[10]. Recently, we developed a novel hydrogen-bonding strategy to build $\mathrm{pH}$-sensitive micelles, using hydrophilic polymer and hydrophobic drug as building blocks [11]. It resulted in a micelle, in which only hydrogen bonds rather than covalent bonds existed between core and shell. Further, it achieved the integration of drug-loading and self-assembly in preparing drug-loaded micelles, avoiding the multiple steps used in the covalent-bond method. This result aroused our interest to construct a novel non-covalently connected micelle, with inclusion interaction serving as driving force.

We assumed that, if a hydrophilic $\beta$-CD containing polymer and a dimer of hydrophobic drug could form an amphiphilic inclusion complex, with the dimer being partially embedded into the cavity of $\beta$-CD moiety, the complex should be able to self-assemble into a micelle, with dimer as core and the polymer as shell. Meanwhile, it was mentioned that the GSH concentration in human cell (millimolar level) was much higher than that in bloodstream (micromolar level), and that the GSH concentration in tumor cells was at least 4-fold higher than that in normal cells [12]. Therefore, if we chose the dimer that two monomer units were joined by a disulfide bond, it would be able to remain stable in bloodstream, and become easy to cleavage once the micelle had entered into tumor cells, and the controlled release of drug might be achieved.

Based on the above assumptions, dimer of 6-mercaptopurine (DMP) was determined. First, from the chemical structure, DMP was a homodimer consisting of two 6-mercaptopurine (6-MP) monomers joined by a disulfide bond. Second, DMP had good hydrophobility and could form an inclusion complex with $\beta$-CD with its molecule being partially embedded into the cavity of $\beta$-CD. Third, 6-MP was an anti-cancer drug with low bioavailability (about $16 \%)$ as well as short plasma half-time $(0.5-1.5 \mathrm{~h})$, due to its poor solubility and a free sulfhydryl group easily reacting with the plasma proteins [13]. With the micellization of DMP, these two defects could be avoided.

Carboxymethyl chitosan (CMCS), obtained from carboxymethylation of chitosan, was also determined. On one hand, CMCS was biopolymer with good aqueous solubility, low toxicity and good biocompatibility [14]. On the other hand, it was reported that polymeric micelles with CMCS as shells usually could swell in slightly acid aqueous solution, due to a lot of reversibly ionized groups existing in their structures [10]. Taking account of the slightly acid intracellular environments of tumor cells (lysosome $\mathrm{pH} 4.5$ - 5.0 and endosome $\mathrm{pH} 5.0$ - 6.5) [15], this result might contribute to exposing the disulfide bonds in the core of the micelle to the GSH in tumor cells.

The aim of this study was to employ an inclusion-interaction assembly strategy to construct a novel $\mathrm{pH} / \mathrm{redox}$ responsive micelle system for controlled release of 6-MP. At first, a hydrophilic $\beta$-CD grafted carboxymethyl chitosan (CMCS-g- $\beta$-CD) and a dimer of 6-MP were synthesized. Then, an amphiphilic inclusion complex (CMCS-g- $\beta$-CD-DMP) was prepared with the dimer being partially embedded into the cavity of $\beta$-CD moiety. It self-assembled into micelles in distilled water. Their structure and morphology were observed by transmission electron microscopy (TEM). The stability, $\mathrm{pH}$-sensitivity and reduction-response were investigated by dynamic light scattering (DLS). Their stimuli-responsive release properties and anti-tumor activity were also studied.

\section{Materials and Methods}

\subsection{Materials}

Chitosan (CS, MW: $560 \mathrm{kDa}$, degree of decetylation: 91\%) was purchased from Yuhuan Ocean Biochemical Co., Ltd. (Zhejiang, China). N-(3-Dimethylaminopropyl)-N'-ethylcarbodiimide (EDC), $\beta$-Cyclodextrin ( $\beta$-CD), $\mathrm{N}$-Hydroxysuccinimide (NHS) and 6-Mercaptopurine (6-MP) were all purchased from Aladdin Reagent Inc. (Shanghai, China). All other chemical reagents were of analytical grade and used without further purification. HeLa cells were purchased from American Type Culture Collection (ATCC) and grown in Dulbecco's Modified Eagel medium (DMEM) containing 10\% FBS.

\subsection{Synthesis of CMCS}

Chitosan $(10.0 \mathrm{~g})$ was stirred with $100 \mathrm{~mL}$ isopropanol at room temperature for $24 \mathrm{~h}$. This solution was then fil- 
tered and the filter residue was added with $40 \mathrm{~mL} \mathrm{NaOH}$ aqueous solution $(50 \mathrm{wt} \%$ ). The mixture was stirred for $1 \mathrm{~h}$ and placed into a refrigerator at $-20^{\circ} \mathrm{C}$ for $24 \mathrm{~h}$. After the frozen mixture was thawed, chloroacetic acid (20.0 g) dissolved in $20 \mathrm{~mL}$ isopropanol was dropwise added. This solution was stirred overnight below $10^{\circ} \mathrm{C}$ and then filtered. The filter residue was dialyzed (MWCO 14,000) against distilled water and lyophilized to obtain CMCS. The degree of substitution (DS) of carboxymethyl groups was determined as $\sim 34 \%$ by ${ }^{1} \mathrm{H}-\mathrm{NMR}$.

\subsection{Synthesis of $\mathrm{CM} \beta$-CD}

$\beta$-CD $(5.68 \mathrm{~g})$ was stirred with $40 \mathrm{~mL} \mathrm{NaOH}$ aqueous solution $(25 \mathrm{wt} \%)$ in a three-necked flask at $65^{\circ} \mathrm{C}$ for $1 \mathrm{~h}$. Then, chloroacetic acid $(0.473 \mathrm{~g})$ dissolved in $10 \mathrm{~mL}$ distilled water was dropwise added into the flask with stirring. The mixture was stirred at $65^{\circ} \mathrm{C}$ for $8 \mathrm{~h}$. Then, the reaction mixture was neutralized and precipitated with excess amount of methyl alcohol. After the precipitate was collected and dried, $\mathrm{CM} \beta$-CD was obtained. The DS of carboxymethyl groups was determined as $\sim 76 \%$ by ${ }^{1} \mathrm{H}-\mathrm{NMR}$.

\subsection{Synthesis of DMP}

DMP was synthesized following the method mentioned in the literature [16]. 6-Mercaptopurine $(0.500 \mathrm{~g})$ was dissolved in $300 \mathrm{~mL} \mathrm{pH} 7.6$ phosphate buffer solution (PBS) at $60^{\circ} \mathrm{C}$. After the solution was cooling down, $0.406 \mathrm{~g} \mathrm{I}_{2}$ dissolved in $2 \mathrm{~mL}$ DMSO was dropwise added. This solution was stirred for $2 \mathrm{~h}$ at room temperature. Then, the light yellow precipitate was collected by filtration and washed by distilled water $(4 \times 100 \mathrm{~mL})$. The precipitate was then dried and DMP was obtained.

\subsection{Synthesis of CMCS-g- $\beta$-CD}

$\mathrm{CM} \beta$-CD $(2.39 \mathrm{~g}), \mathrm{EDC}(0.384 \mathrm{~g})$ and NHS $(0.230 \mathrm{~g})$ were dissolved in $60 \mathrm{~mL}$ distilled water and stirred for 1 $\mathrm{h}$ at room temperature. Then, CMCS $(0.328 \mathrm{~g})$ dissolved in $15 \mathrm{~mL}$ distilled water was dropwise added into the solution where the $\mathrm{pH}$ value was maintained at 7 . The solution was stirred for another $6 \mathrm{~h}$ and then dialyzed (MWCO 14,000) against distilled water for $72 \mathrm{~h}$. The dialysate was lyophilized and CMCS-g- $\beta$-CD was obtained. The DS was determined as $\sim 59 \%$ by ${ }^{1} \mathrm{H}-\mathrm{NMR}$.

\subsection{Preparation of CMCS-g- $\beta$-CD·DMP}

CMCS-g- $\beta$-CD (1.39 g) was dissolved in $100 \mathrm{~mL}$ PBS (pH 7.4) at $60^{\circ} \mathrm{C}$. DMP of various amounts $(0.151 \mathrm{~g}$, $0.302 \mathrm{~g}$ and $0.453 \mathrm{~g}$ ) were dissolved in $2 \mathrm{~mL}$ DMSO and then respectively added into the solutions with stirring. The reaction mixtures were stirred for $6 \mathrm{~h}$ and then dialyzed (MWCO 14,000) against distilled water for $8 \mathrm{~h}$. After the dialysates were freeze-dried, CMCS-g- $\beta$-CD-DMP with various DMP contents were obtained. Their drug contents were determined by elementary analysis, as summarized in Table 1.

\subsection{Characterization}

The FT-IR spectra of CS, CMCS, $\beta$-CD, CM $\beta$-CD, DMP, CMCS-g- $\beta$-CD, the physical mixture of CMCSg- $\beta$-CD and DMP and CMCS-g- $\beta$-CD-DMP were determined by a FT-IR spectrometer (Avator 360, Nicolet, MA, USA) using $\mathrm{KBr}$ pellets. The ${ }^{1} \mathrm{H}-\mathrm{NMR}$ spectra of CMCS, CMCS-g- $\beta$-CD, CMCS-g- $\beta$-CD-DMP were determined on a Varian 600 spectrometer (Varian, USA) at $600 \mathrm{MHz}$ using $\mathrm{D}_{2} \mathrm{O}$ as solvents. The DSC profiles of the physical mixture of CMCS-g- $\beta$-CD and DMP, CMCS-g- $\beta$-CD-DMP and CMCS-g- $\beta$-CD were determined by a DSC calorimeter $\left(200 \mathrm{~F} 3\right.$, NETZSCH, German) with a temperature range of $60^{\circ} \mathrm{C}-180^{\circ} \mathrm{C}$.

\subsection{Fabrication and Characterization of CMCS-g- $\beta$-CD·DMP Micelles}

CMCS-g- $\beta$-CD·DMP (0.01 g) was dispersed in $10 \mathrm{~mL} \mathrm{PBS} \mathrm{(pH} \mathrm{7.4)} \mathrm{and} \mathrm{stirred} \mathrm{at} \mathrm{room} \mathrm{temperature} \mathrm{for} 0.5 \mathrm{~h}$.

Table 1. Characteristic data of CMCS-g- $\beta$-CD·DMP with different DMP contents.

\begin{tabular}{ccc}
\hline Samples & DMP/ CMCS-g- $\beta$-CD (mol/mol) & DMP content (mg/100mg) \\
\hline CMCS-g- $\beta$-CD·DMP1 & $0.5: 1$ & $7.34 \pm 0.24$ \\
CMCS-g- $\beta$-CD·DMP2 & $1.0: 1$ & $9.37 \pm 0.36$ \\
CMCS-g- $\beta$-CD-DMP3 & $1.5: 1$ & $10.21 \pm 0.54$ \\
\hline
\end{tabular}


Then, this dispersion was sonicated by a probe type sonifer (JY92-2D, made by Ningbo Xinzhi Bio-tech Co., $\mathrm{Ltd})$ at $60 \mathrm{~W}$ for $3 \mathrm{~min}$ and a CMCS-g- $\beta$-CD·DMP micelle solution was obtained. The micelles prepared from CMCS-g- $\beta$-CD·DMP1, CMCS-g- $\beta$-CD·DMP2 and CMCS-g- $\beta$-CD·DMP3 were named M-1, M-2 and M-3, respectively. Their mean diameters and distributions were determined by DLS using a Nano-ZS3600 (Malvern, UK). All measurements were performed with a wavelength of $670 \mathrm{~nm}$, a detector angle of $90^{\circ}$ and a temperature of $25^{\circ} \mathrm{C}$. The morphology of the micelles was observed by TEM using a JEM-100CX11 (JEOL, Japan).

\subsection{Stability Studies of CMCS-g- $\beta$-CD-DMP Micelles}

The stability study of CMCS-g- $\beta$-CD·DMP micelles was performed by DLS. The micelle dry powders $(0.01 \mathrm{~g})$ were dispersed in $10 \mathrm{~mL}$ PBS (pH 7.4) and placed for 30 days at room temperature. Their mean diameters and distributions before and after storage were measured.

\subsection{0. pH-Sensitivity and Reduction-Response of CMCS-g- $\beta$-CD-DMP Micelles}

The $\mathrm{pH}$-sensitivity of the micelles was studied in media at various $\mathrm{pH}$ values. The micelle dry powders $(0.01 \mathrm{~g})$ were respectively dispersed in $10 \mathrm{~mL}$ PBS with various $\mathrm{pH}$ values. Then, these dispersions were incubated in a shake bed at a shaking speed of $60 \mathrm{rpm}$ at $37^{\circ} \mathrm{C}$ for 1 day. The mean diameters and distributions of the micelles were then measured by DLS.

The reduction-response of the micelles was investigated in media containing different GSH concentrations. The micelle dry powders $(0.01 \mathrm{~g})$ were respectively dissolved in $10 \mathrm{~mL} \mathrm{pH} 7.4$ PBS containing different GSH concentrations. Afterwards, the solutions were incubated in a shake bed at $37^{\circ} \mathrm{C}$ and $60 \mathrm{rpm}$ for 1 day. The mean diameters and distributions of the micelles were then determined by DLS.

\subsection{Stimuli-Responsive Release of 6-MP from the Micelles}

The stimuli-responsive release of 6-MP from the micelles was investigated in three different release media: 1) pH 7.4 PBS with $10 \mu \mathrm{M}$ GSH; 2) pH 7.4 PBS with $5 \mathrm{mM} \mathrm{GSH}$; 3) pH 5.0 acetate buffer with $20 \mathrm{mM}$ GSH. The micelle dry powders $(0.01 \mathrm{~g})$ were dispersed in $10 \mathrm{~mL}$ release medium and straightway moved to a dialysis bag (MWCO 14,000). The dialysis bag was then immediately immersed in $40 \mathrm{~mL}$ release medium and oscillated in a shake bed at $60 \mathrm{rpm}$ and $37^{\circ} \mathrm{C}$. At different time intervals, $2 \mu \mathrm{L}$ of release medium was taken out and $2 \mu \mathrm{L}$ of fresh medium was added. The medium taken out before was then analyzed by HPLC. The cumulative release rate of 6-MP was calculated using the following equation:

$$
\text { Cumulative release rate }(\%)=\mathrm{M}_{\mathrm{t}} / 1.007 \mathrm{M}_{0} \times 100 \%
$$

where $M_{t}$ refers to the amount of 6-MP released at time $t$ and $M_{0}$ refers to the total amount of DMP in micelles.

\subsection{Anti-Tumor Activity of CMCS-g- $\beta$-CD-DMP Micelles}

MTT assay was employed to study the anti-tumor activity of CMCS-g- $\beta$-CD-DMP micelles. HeLa cells were seeded onto a 96-well plate in DMEM containing $10 \%$ FBS with a density of $1 \times 10^{4}$ cells/well. The cells were incubated at $37^{\circ} \mathrm{C}$ for 1 day and exposed to $20 \mu \mathrm{L}$ dispersions of micelles, and $20 \mu \mathrm{L}$ dispersions of 6-MP and CMCS-g- $\beta$-CD with equivalent concentration. A $20 \mu \mathrm{L}$ buffer was also added and used as a control. The cells were incubated for another $48 \mathrm{~h}$. Then, $10 \mu \mathrm{L}$ MTT solutions $(5 \mathrm{mg} / \mathrm{mL})$ were added into each well. After the cells were incubated for $4 \mathrm{~h}, 10 \mu \mathrm{L}$ DMSO was added to each well to dissolve the formazan crystals. Finally, the optical densities (OD) were observed by a microplate reader at $570 \mathrm{~nm}$. The inhibition ratios were calculated using following equation:

$$
\text { Inhibition ratio }(\%)=\left(\mathrm{OD}_{1}-\mathrm{OD}_{2}\right) / \mathrm{OD}_{1} \times 100 \%
$$

where $\mathrm{OD}_{1}$ refers to optical density of the control and $\mathrm{OD}_{2}$ refers to the optical densities of the cells exposed to the micelles, 6-MP and CMCS-g- $\beta$-CD.

\section{Results and Discussion}

\subsection{Preparation and Structural Analysis of CMCS-g- $\beta$-CD-DMP}

The synthetic route of CMCS-g- $\beta$-CD·DMP was shown in Figure 1. Firstly, CS and $\beta$-CD were modified with 


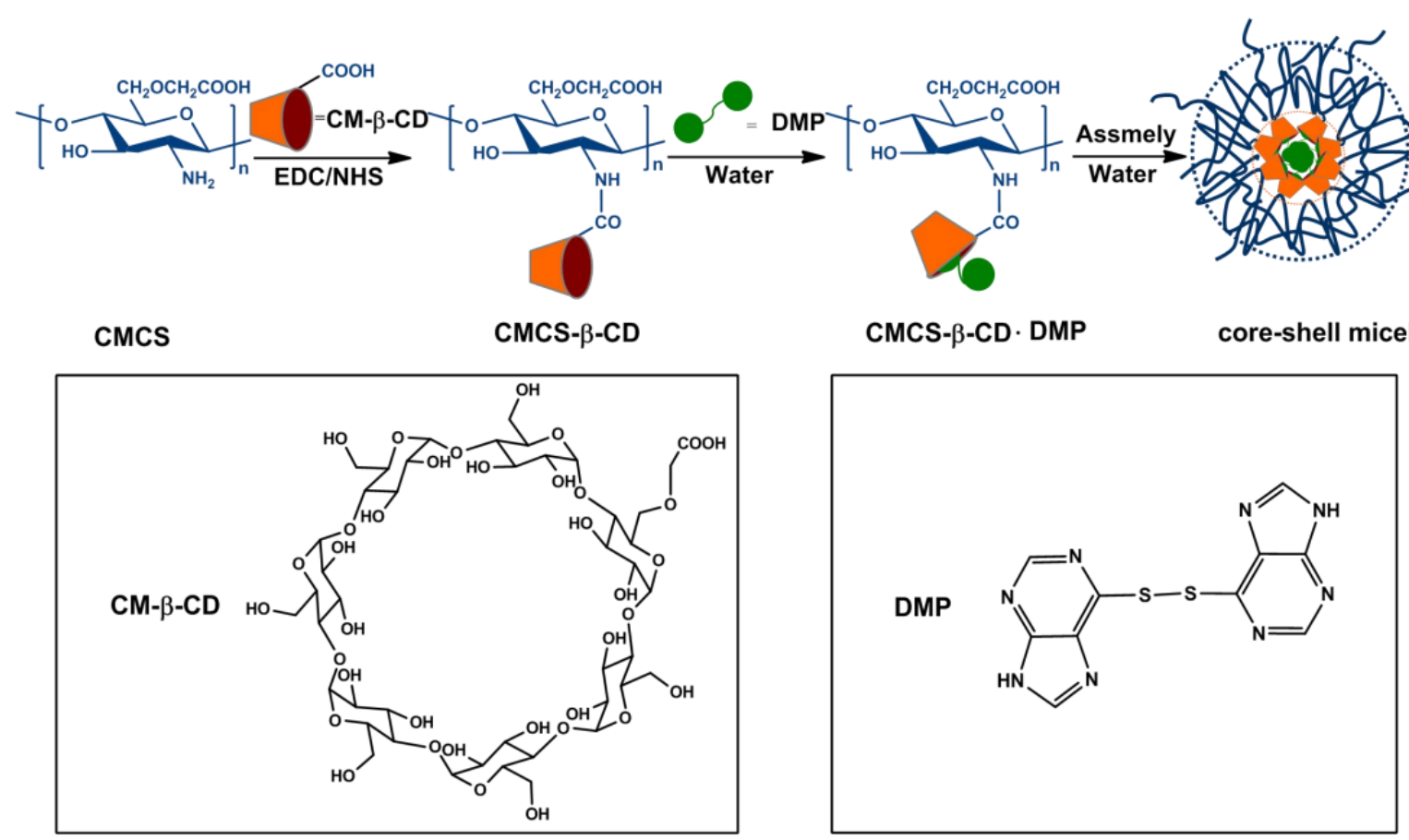

Figure 1. Synthetic route and assembly process of CMCS-g- $\beta$-CD·DMP.

chloroacetic acid to obtain CMCS and CM $\beta$-CD. Then, CMCS-g- $\beta$-CD was obtained via the formation of amide bonds between the carboxyl groups of $\mathrm{CM} \beta$-CD and the amino groups of CMCS. At last, CMCS-g$\beta$-CD DMP was synthesized with DMP being partially embedding into the cavity of $\beta$-CD moiety.

The FT-IR spectra of CS, CMCS, $\beta$-CD, CM $\beta$-CD, DMP, CMCS-g- $\beta$-CD, the physical mixture of DMP and CMCS-g- $\beta$-CD (DMP content 9.37 wt\%), 6-MP and CMCS-g- $\beta$-CD·DMP2 were shown in Figure 2. Compared with the spectrum of CS, the new characteristic bands at $1596 \mathrm{~cm}^{-1}$ and $1406 \mathrm{~cm}^{-1}$ appeared in the spectrum of CMCS were assigned to the symmetry and asymmetry stretching vibrations of $\mathrm{COO}-$, indicating that carboxymethyl groups had been grafted onto chitosan. In the spectrum of $\mathrm{CM} \beta$ - $\mathrm{CD}$, the characteristic band at 1720 $\mathrm{cm}^{-1}$ was ascribed to stretching vibration of carbonyl group $(\mathrm{C}=\mathrm{O})$. This band was not observed in the spectrum of $\beta$-CD, confirming that carboxymethyl group was grafted onto $\beta$-CD. The spectrum of CMCS-g- $\beta$-CD exhibited a characteristic band at $3426 \mathrm{~cm}^{-1}$ which was much higher than that of CMCS. This result was assigned to the existence of more hydroxyl groups in its structure resulting from grafting of $\mathrm{CM} \beta$-CD. In addition, the characteristic bands of $\alpha$-pyranyl vibration of CM $\beta$-CD at $946.2 \mathrm{~cm}^{-1}$ and $\beta$-pyranyl vibration of CMCS at 849.9 $\mathrm{cm}^{-1}$ both appeared in curve e, which also confirmed that $\mathrm{CM} \beta$-CD was grafted onto CMCS. Compared with the spectrum of 6-MP, the characteristic band of thiol groups at $2564 \mathrm{~cm}^{-1}$ disappeared in the spectrum of DMP, indicating that 6-MP had been oxidized to DMP. The two characteristic bands at $604 \mathrm{~cm}^{-1}$ and $638 \mathrm{~cm}^{-1}$ in the spectrum of DMP were assigned to the existence of 6-MP moiety. However, in the spectrum of CMCS-g- $\beta$-CDDMP2, these two bands shifted to $646 \mathrm{~cm}^{-1}$ and $668 \mathrm{~cm}^{-1}$, while these two bands in the spectrum of the physical mixture remained unchanged. This result indicated the formation of the inclusion complex between CMCS-g$\beta$-CD and DMP.

The DSC data shown in Figure 3 further supported the result. In the DSC profile of CMCS-g- $\beta$-CD, a broad endothermic peak could be observed, which was related to water evaporation. However, in the profile of the inclusion complex, the peak that represented water loses was vastly reduced in intensity and shifted to a lower temperature. This result suggested that a structure of lower water capacity was formed, because of the extrusion of water molecules from $\beta$-CD cavities, resulting from DMP being embedded into $\beta$-CD cavities [17].

The ${ }^{1} \mathrm{H}-\mathrm{NMR}$ spectra of CMCS, CMCS-g- $\beta$-CD and CMCS-g- $\beta$-CD·DMP in $\mathrm{D}_{2} \mathrm{O}$ were shown in Figure 4. Compared with curve a, the new signals in the region of $5.0-5.2 \mathrm{ppm}$ in curve $\mathrm{b}$ could be ascribed to the existence of D-glucopyranosyl residues of $\beta$-CD, suggesting that $\beta$-CD was successfully grafted onto CMCS. The signals at $3.86-3.90 \mathrm{ppm}$ and $3.61-3.64 \mathrm{ppm}$ in curve $\mathrm{b}$ were respectively assigned to two protons positioned 

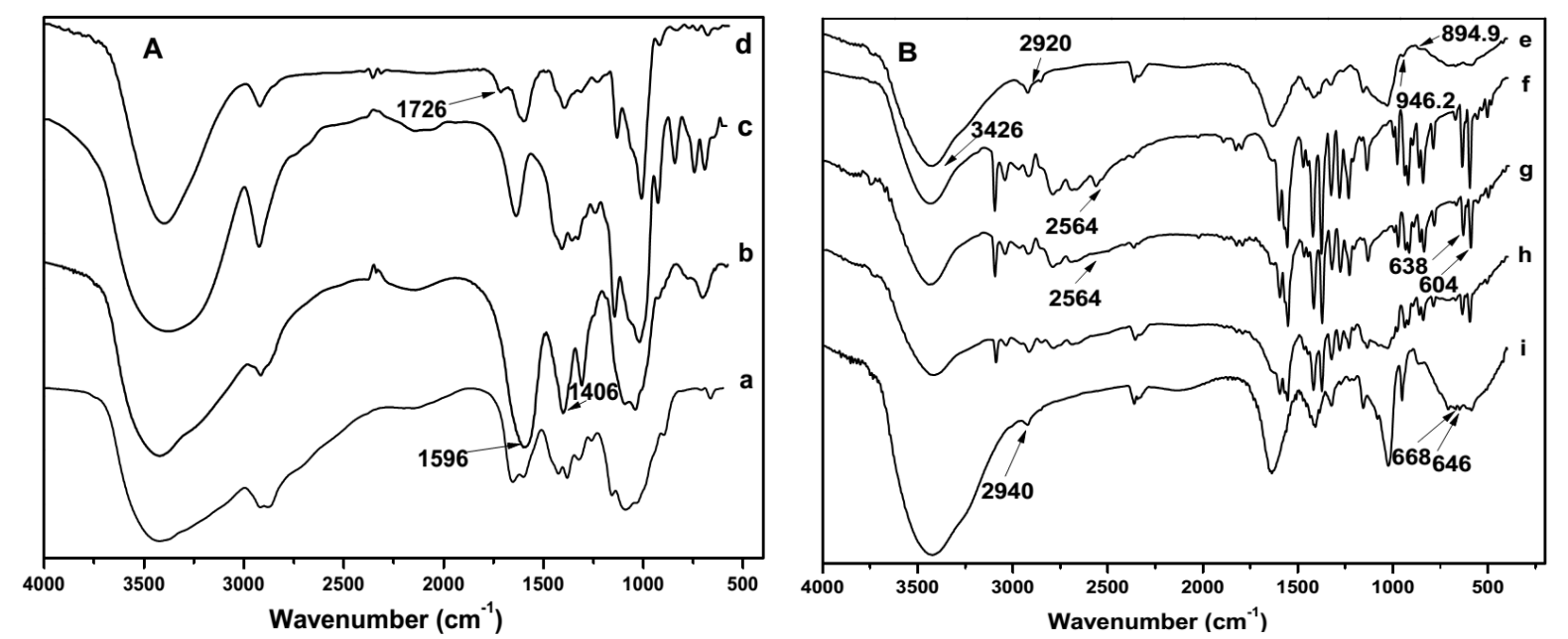

Figure 2. (A) FT-IR spectra of (a) CS, (b) CMCS, (c) $\beta$-CD and (d) CM $\beta$-CD; (B) FT-IR spectra of (e) CMCS-g- $\beta$-CD, (f) 6-MP, (g) DMP, (h) physical mixture of CMCS-g- $\beta$-CD and DMP (DMP content $9.37 \mathrm{wt} \%$ ) and (i) CMCS-g- $\beta$-CD $-\mathrm{DMP} 2$.

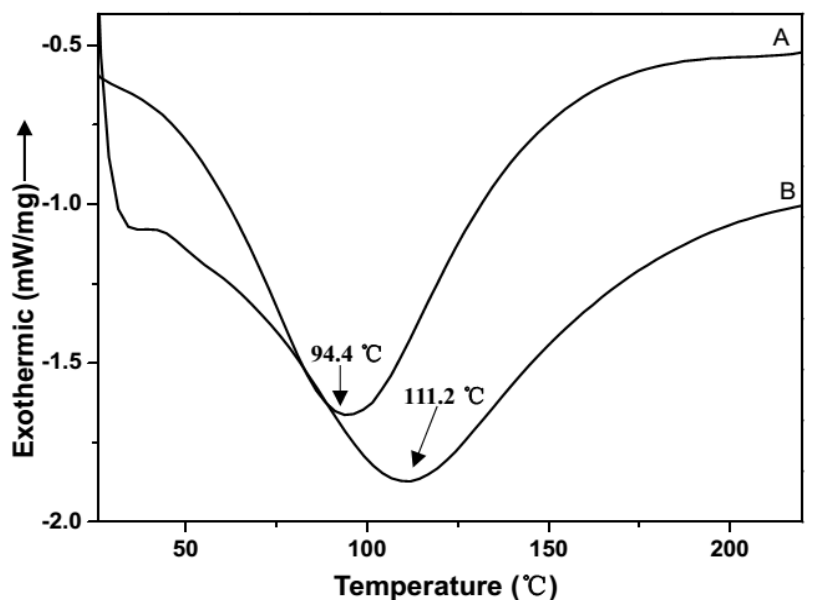

Figure 3. DSC curves of (A) CMCS-g- $\beta$-CD·DMP2 and (B) CMCS-g- $\beta$-CD.
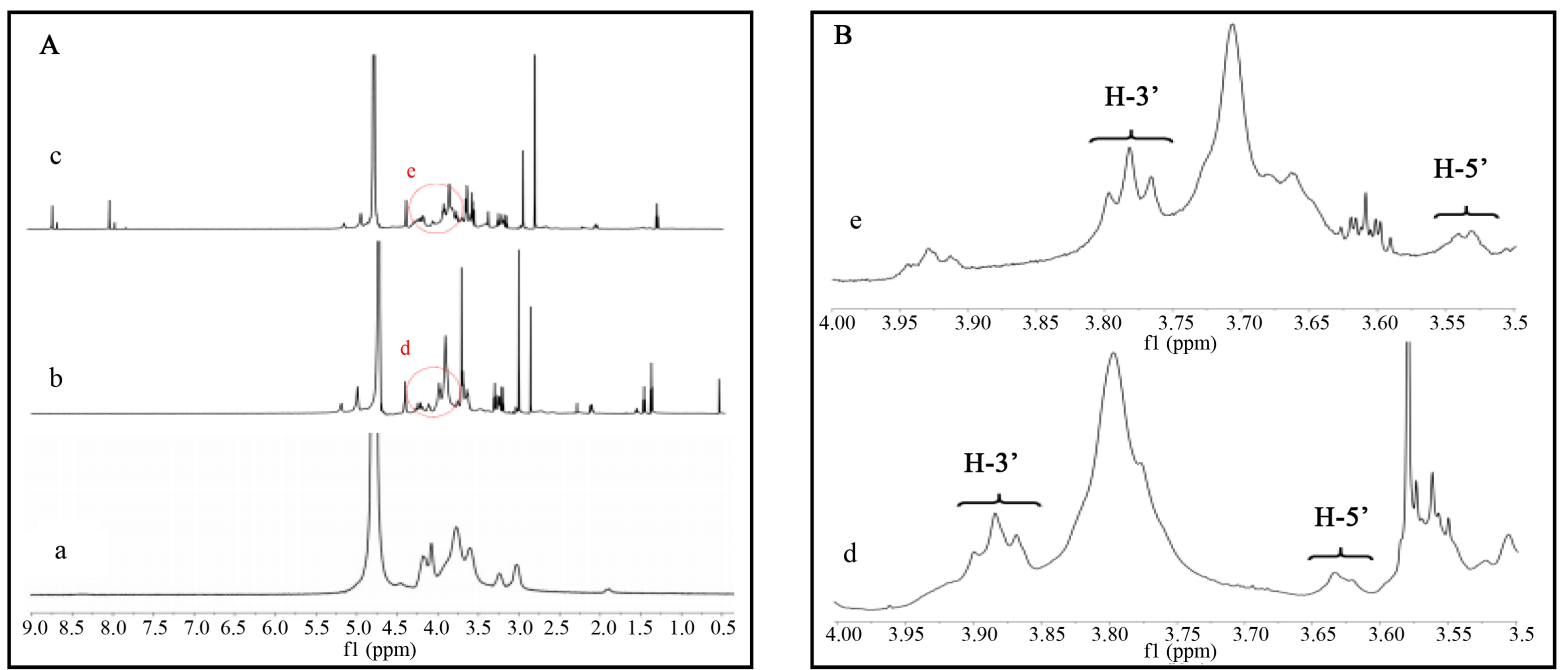

Figure 4. (A) ${ }^{1} \mathrm{H}-\mathrm{NMR}$ spectra in $\mathrm{D}_{2} \mathrm{O}$ of (a) CMCS, (b) CMCS-g- $\beta$-CD and (c) CMCS-g- $\beta$-CD-DMP; (B) Enlarge figures of the regions of (d) and (e). 
inside the $\beta$-CD cavity, namely $\mathrm{H}-3$ ' and $\mathrm{H}-5$ '. In curve $\mathrm{c}$, the signals of $\mathrm{H}-3$ ' and $\mathrm{H}-5$ ' respectively shifted to $3.74-3.80 \mathrm{ppm}$ and $3.51-3.54 \mathrm{ppm}$. This result was related to the ring-current of the aromatic ring that was embedded into $\beta$-CD cavity, suggesting the formation of an inclusion complex between CMCS-g- $\beta$-CD and DMP [18]. Furthermore, the strong signals at $8.28 \mathrm{ppm}$ and $9.05 \mathrm{ppm}$ in curve c could be ascribed to the DMP moiety which was located outside the $\beta$-CD cavity and the signals of the DMP moiety positioned inside the $\beta$ $\mathrm{CD}$ cavity shifted to $8.21 \mathrm{ppm}$ and $8.99 \mathrm{ppm}$. These results confirmed the formation of the inclusion complex and the DMP was only partially embedded into the cavity of $\beta$-CD moiety.

\subsection{Fabrication and Characterization of CMCS-g- $\beta$-CD-DMP Micelles}

The fabrication procedures of the core-shell micelles were illustrated in Figure 1. Amphiphilic CMCS-g- $\beta$ CD·DMP was firstly synthesized and then underwent self-assembly to form a core-shell micelle. The TEM image of M-2 in pH 7.4 PBS was shown in Figure 5. It could be found that the micelles had a spherical core-shell configuration with a mean diameter of about $160 \mathrm{~nm}$. Table 2 showed the DLS data of M-2 in pH 7.4 PBS. It could be easily found that diameter measured by DLS $(194.7 \mathrm{~nm})$ was larger than that $(160 \mathrm{~nm})$ by TEM. This might be attributed to the swelling of the micelles in water during DLS testing.

With DMP being partially embedded into the cavity of $\beta$-CD moiety, the non-covalently connected complex CMCS-g- $\beta$-CD·DMP obtained an amphiphilic macromolecule composed of a hydrophilic polymer backbone and hydrophobic DMP moieties that were located outside $\beta$-CD. After it dissolved in water, driven by the strong hydrophobic interactions, these hydrophobic drug moieties rapidly self-aggregated to form a hydrophobic core. And then, because of a high affinity with water, those hydrophilic polymer chains extended in the water and then frizzled to form a hydrophilic shell on the surface of the hydrophobic core. It should be noted that these inter- and/or intra-molecular hydrogen bonds in the hydrophilic shell also promoted the assembly process by increasing the stability of the shell [19] [20].

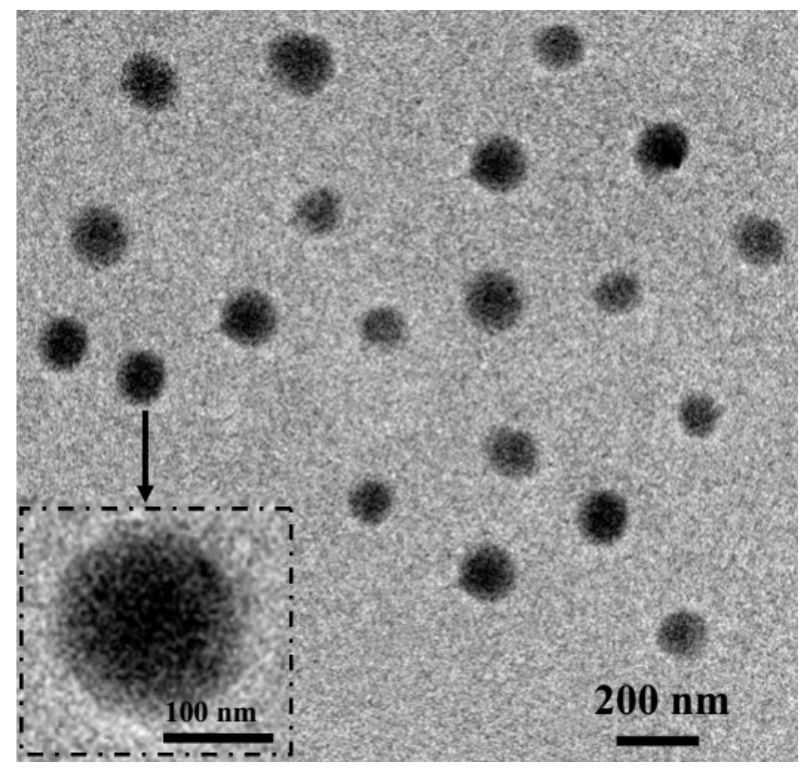

Figure 5. TEM image of M-2 in $\mathrm{pH} 7.4$ PBS.

Table 2. The mean diameters and distributions of the micelles in $\mathrm{pH} 7.4$ PBS for their stability.

\begin{tabular}{ccccc}
\hline & \multicolumn{2}{c}{ Before storage } & \multicolumn{2}{c}{ After storage } \\
\cline { 2 - 5 } Sample & MD (nm) & PDI & MD (nm) & PDI \\
M-1 & $214.5 \pm 2.6$ & $0.066 \pm 0.041$ & $229.8 \pm 3.6$ & $0.093 \pm 0.023$ \\
M-2 & $194.7 \pm 1.8$ & $0.082 \pm 0.018$ & $204.3 \pm 4.5$ & $0.086 \pm 0.018$ \\
M-3 & $148.4 \pm 2.1$ & $0.076 \pm 0.023$ & $153.6 \pm 3.4$ & $0.096 \pm 0.036$ \\
\hline
\end{tabular}




\subsection{Stability of CMCS-g- $\beta$-CD-DMP Micelles}

The stability study of the micelles was performed using DLS by placing the micelles in pH 7.4 PBS for 30 days. Before and after storage, their mean diameters and distributions were both determined and summarized in Table 2. It could be easily found that the micelles only had little diameter and polydispersity index (PDI) value change which indicated the micelles had good stability. This result might be ascribed to the formation of intra- and/or inter-molecular hydrogen bonds in the hydrophilic shell which made the micelles a non-covalently cross-linked hydrogel configuration.

\section{4. pH-Sensitivity of CMCS-g- $\beta$-CD-DMP Micelles}

The changes of the micelle diameters with $\mathrm{pH}$ alteration determined by DLS were shown in Figure 6. As the $\mathrm{pH}$ value increased from 3.0 to 6.0, the mean diameters of the three samples increased significantly and reached a maximum value at $\mathrm{pH}$ 6.0. This might be attributed to increasing of protonation of the carboxyl groups in the shells. After being protonated, the polysaccharide chains would become more hydrophilic and tend to repulse each other which finally led to a swell of the hydrophilic shell. As the $\mathrm{pH}$ value further increased to 8.0, however, a sudden decrease of particle diameters was observed, which could be attributed to the weaker electrostatic repulsion weakened by the charge screening effect of counter ions.

\subsection{Reduction-Response of CMCS-g- $\beta$-CD-DMP Micelles}

The reduction-response of the micelles was investigated by DLS in media containing various concentrations of GSH $(0,10 \mu \mathrm{M}, 5 \mathrm{mM}$ and $20 \mathrm{mM})$. As shown in Table 3, compared with the media without GSH, mean

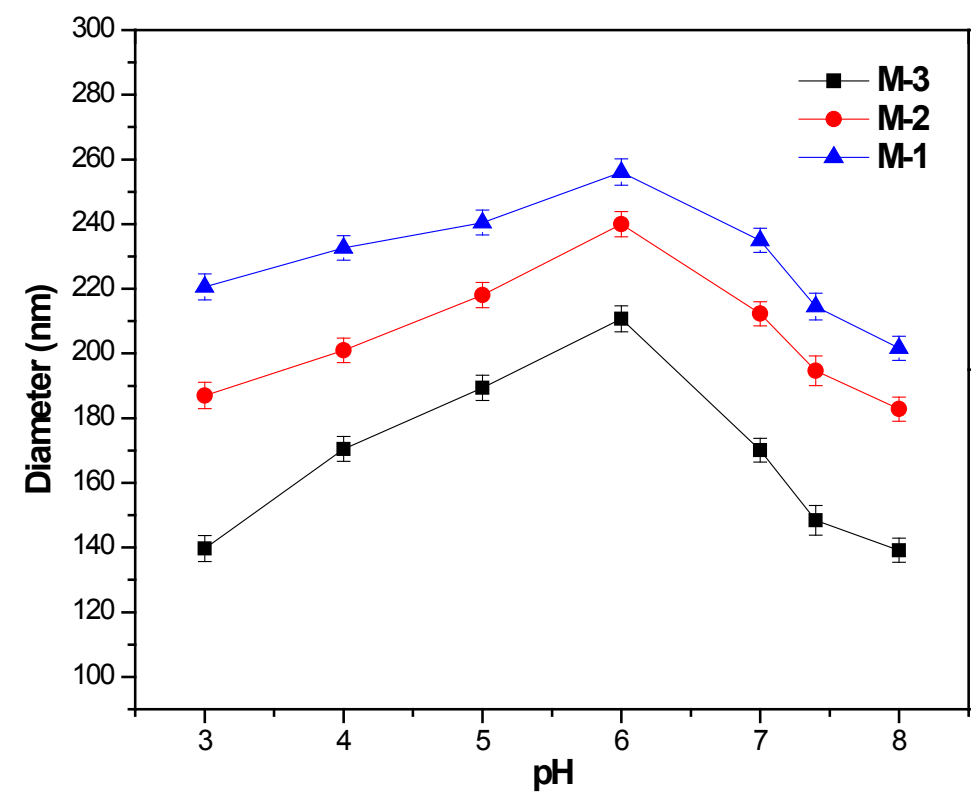

Figure 6. pH-sensitivity of the micelles.

Table 3. The mean diameters and distributions of the micelles in $\mathrm{pH} 7.4$ media with various concentrations of GSH for $24 \mathrm{~h}$.

\begin{tabular}{|c|c|c|c|c|c|c|c|c|}
\hline \multirow{2}{*}{ Sample } & \multicolumn{2}{|c|}{ GSH $(0 \mu \mathrm{M})$} & \multicolumn{2}{|c|}{ GSH $(10 \mu \mathrm{M})$} & \multicolumn{2}{|c|}{ GSH (5 mM) } & \multicolumn{2}{|c|}{ GSH (20 mM) } \\
\hline & $\mathrm{MD}(\mathrm{nm})$ & PDI & $\mathrm{MD}(\mathrm{nm})$ & PDI & $\mathrm{MD}(\mathrm{nm})$ & PDI & $\mathrm{MD}(\mathrm{nm})$ & PDI \\
\hline M-1 & 214.5 & 0.066 & 224.6 & 0.076 & 339.2 & 0.245 & 565.4 & 0.354 \\
\hline M-2 & 194.7 & 0.082 & 191.7 & 0.089 & 307.1 & 0.269 & 532.3 & 0.373 \\
\hline M-3 & 148.4 & 0.076 & 159.4 & 0.079 & 249.3 & 0.276 & 479.5 & 0.391 \\
\hline
\end{tabular}


diameters and PDI values of the micelles in the buffer with $10 \mu \mathrm{M}$ GSH changed little after incubated for $24 \mathrm{~h}$. As the GSH concentration increased to $5 \mathrm{mM}$, it could be easily found that an obvious increase appeared in both particle diameters and PDI values. Furthermore, a larger increase could be observed when the GSH concentration increased to $20 \mathrm{mM}$. These data indicated that the particle diameters and PDI values of the micelles increased with the increase of GSH concentration in aqueous solution.

\subsection{Stimuli-Responsive Release of 6-MP from the Micelles}

The stimuli-responsive release of 6-MP from the micelles was investigated with M-2. As shown in Figure 7, 6-MP cumulative release from the micelles was about $27.3 \mathrm{wt} \%$ in pH $7.4 \mathrm{PBS}$ with $10 \mu \mathrm{M}$ GSH (mimicking the blood circulation) after $48 \mathrm{~h}$. When the GSH concentration increased to $5 \mathrm{mM}$ (mimicking the intracellular environment of normal cell), it showed that 6-MP release reached over $59 \mathrm{wt} \%$ after $48 \mathrm{~h}$. In pH 5.0 medium with $20 \mathrm{mM} \mathrm{GSH}$ (mimicking the intracellular environment of tumor cell), it exhibited a much rapider release to over $22 \mathrm{wt} \%$ in initial $1 \mathrm{~h}$, and over $46 \mathrm{wt} \%$ in $3 \mathrm{~h}$, and finally reached over $88 \mathrm{wt} \%$ after $48 \mathrm{~h}$. These data indicated that the CMCS-g- $\beta$-CD·DMP micelles were likely to remain stable in blood circulation, and could achieve selective and fast drug release responding to the higher GSH concentration and lower $\mathrm{pH}$ value in tumor cells.

The release mechanism of hydrophobic 6-MP was highly dependent on diffusion process and degradation of the micelles. 6-MP could be released from DMP through two procedures. The first was that via an exchange reaction between DMP and GSH, one 6-MP was released in free form and the other was released in form of 6-MP-GSH. After that, 6-MP-GSH could again release free 6-MP by an exchange reaction with another GSH [7]. In pH7.4 PBS with $10 \mu \mathrm{M}$ GSH, drug release was likely to obey the diffusion mechanism and was controlled by the swelling degree of the micelles. In pH 7.4 PBS with $5 \mathrm{mM} \mathrm{GSH}$, the release of 6-MP was controlled by the cleavage of disulfide bonds and followed the degradation mechanism. In pH 5.0 acetate buffer with $20 \mathrm{mM} \mathrm{GSH}$, the fast release of 6-MP was mainly because the disulfide bonds in the core were splitted by the GSH of high concentration in the medium. In meantime, we discovered that the particle size of M-2 in pH 5.0 medium was a bit larger than that in $\mathrm{pH} 7.4$ medium. This might be conductive to exposing the disulfide bonds in the hydrophobic core to extern GSH. These two reasons finally led a rapid and nearly complete release of 6-MP.

The effect of drug content on the release behavior of the micelles was investigated in $\mathrm{pH} 7.4$ PBS with $5 \mathrm{mM}$ GSH. As shown in Figure 8, 6-MP cumulative release rate form M- 1 was about $22 \mathrm{wt} \%$ in initial $3 \mathrm{~h}$ and about

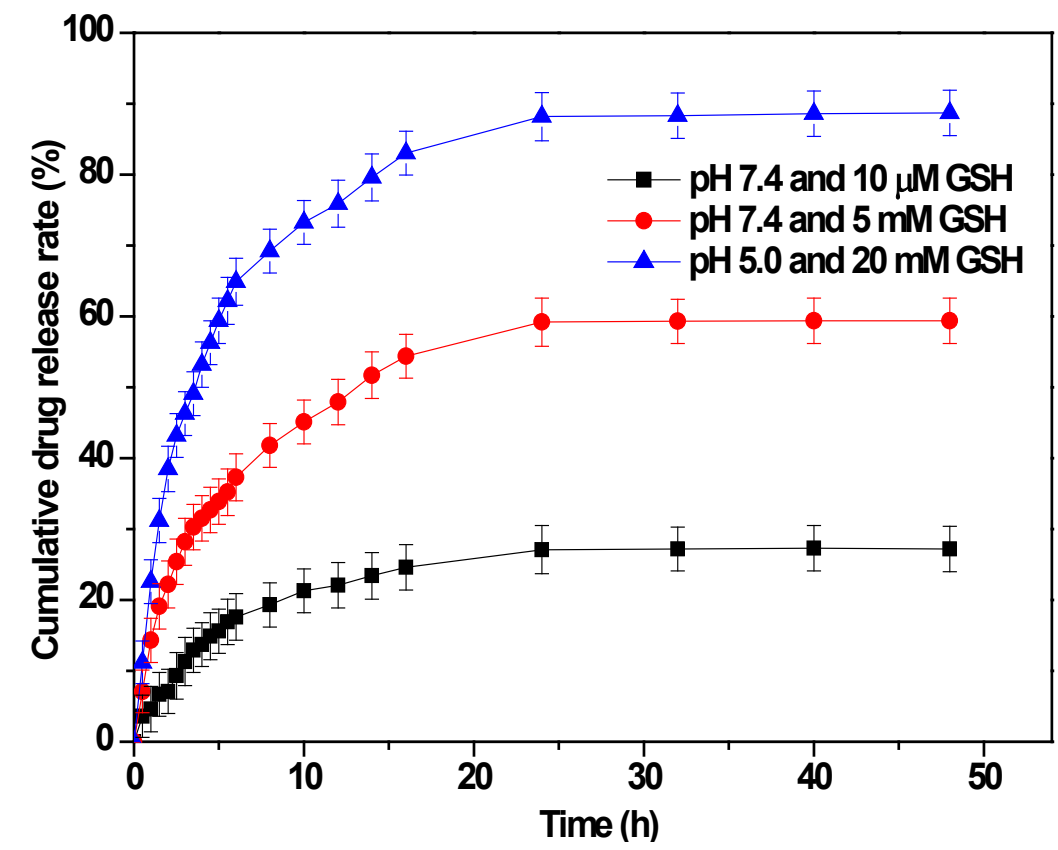

Figure 7. Drug release profiles from M-2 in pH 7.4 PBS with $10 \mu \mathrm{M}$ and $5 \mathrm{mM}$ GSH, and pH 5.0 acetate buffer containing $20 \mathrm{mM}$ GSH in $48 \mathrm{~h}$. 
$50.1 \mathrm{wt} \%$ after $48 \mathrm{~h}$. The release rate from M-2 reached about $28 \mathrm{wt} \%$ in initial $3 \mathrm{~h}$ and over $59 \mathrm{wt} \%$ after $48 \mathrm{~h}$, whereas M-3 reached about $29 \mathrm{wt} \%$ in initial $3 \mathrm{~h}$ and over $69 \mathrm{wt} \%$ after $48 \mathrm{~h}$. The data showed the release rate increased with the increase of drug content in CMCS-g- $\beta$-CD·DMP micelles.

\subsection{Anti-Tumor Activity of CMCS-g- $\beta$-CD-DMP Micelles}

The cytotoxicity of the CMCS-g- $\beta$-CD-DMP micelles was evaluated in HeLa cells using MTT assay. As shown in Figure 9, free 6-MP was employed as a positive control and blank CMCS-g- $\beta$-CD was employed as a negative control. The negative control experiment revealed that CMCS-g- $\beta$-CD was nearly non-toxicity to HeLa cells, indicating the polymer had good biocompatibility. The M-2, however, exhibited a dose-dependent cytotoxicity

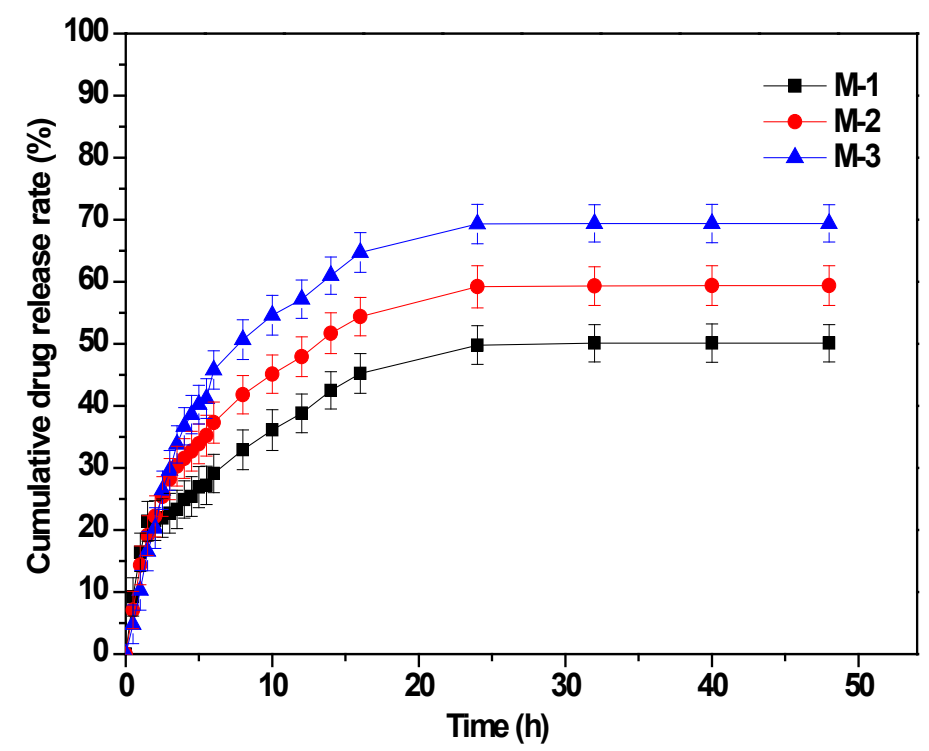

Figure 8. Drug release profiles from the micelles of various DMP contents in $\mathrm{pH}$ 7.4 PBS with $5 \mathrm{mM}$ GSH in $48 \mathrm{~h}$.

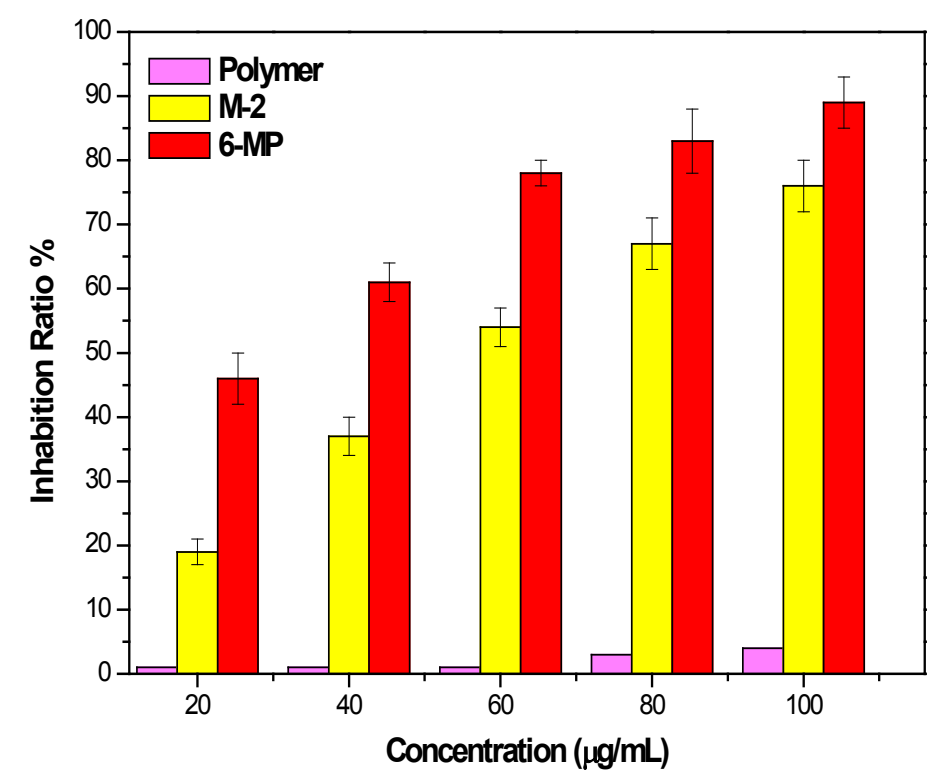

Figure 9. Cell inhibition ratio of in vitro cytotoxicity of $\mathrm{CMCS}-\mathrm{g}-\beta-\mathrm{CD}$, CMCS-g- $\beta$-CD·DMP micelles and free DMP at various concentrations against HeLa cells. 
for HeLa cells which was comparable to that of free 6-MP after incubation for $48 \mathrm{~h}$. This result should be attributed to the fast release of 6-MP from M-2 in intracellular environment of HeLa cells, which confirmed the $\mathrm{pH} /$ redox responsive micelles could be used for controlled release of 6-MP in tumor cells.

\section{Conclusion}

In summary, we had shown that: 1) an inclusion-interaction assembly strategy was used to construct novel $\mathrm{pH} /$ redox responsive micelles, with the drug as the core and the polymer as the shell; this strategy could achieve integration of drug-loading and self-assembly, avoiding the multiple steps used in covalent-bond method; 2) TEM photograph confirmed that the micelles had a spherical core-shell structure; 3) investigations by DLS showed that the micelles were stable in water and had a narrow size distribution as well as a good $\mathrm{pH} /$ redox sensitivity; 4) in vitro drug release showed a selective release in $\mathrm{pH} 5.0$ medium containing $20 \mathrm{mM} \mathrm{GSH}$; 5) in vitro cytotoxicity test showed that the micelles had a dose-dependent toxicity for HeLa cells, indicating that the micelles held great potential for controlled release of 6-MP in tumor cells.

\section{Acknowledgements}

This work was financially supported by Natural National Science Foundation of China (Nos. 51373130, 51273156 and 31300791).

\section{References}

[1] Zhang, J., et al. (2005) Temperature Sensitive Poly[N-isopropylacrylamide-co-(acryloyl $\beta$-cyclodextrin)] for Improved Drug Release. Macromolecular Bioscience, 5, 192-196. http://dx.doi.org/10.1002/mabi.200400167

[2] Thorsteinn, L. and Dominique, D. (2007) Cyclodextrin and Their Pharmaceutical Applications. International Journal of Pharmaceutics, 329, 1-11. http://dx.doi.org/10.1016/j.ijpharm.2006.10.044

[3] He, H., Chen, S., Zhou, J., Dou, Y., Song, L., Che, L., Zhou, X., Chen, X., Jia, Y., Zhang, J., Li, S. and Li, X. (2013) Cyclodextrin-Derived pH-Responsive Nanoparticles for Delivery of Paclitaxel. Biomaterials, 34, 5344-5358. http://dx.doi.org/10.1016/j.biomaterials.2013.03.068

[4] Yuan, Z., Ye, Y., Gao, F., Yuan, H., Lan, M., Lou, K. and Wang, W. (2013) Chitosan-Graft- $\beta$-Cyclodextrin Nanoparticles as a Carrier for Controlled Drug Release. International Journal of Pharmaceutics, 446, 191-198. http://dx.doi.org/10.1016/j.ijpharm.2013.02.024

[5] Zhang, J. and Ma, P. (2013) Cyclodextrin-Based Supramolecular Systems for Drug Delivery: Recent Progress and Future Perspective. Advanced Drug Delivery Reviews, 65, 1215-1233. http://dx.doi.org/10.1016/j.addr.2013.05.001

[6] Wang, J. and Jiang, M. (2006) Polymeric Self-Assembly into Micelles and Hollow Spheres with Multiscale Cavities Driven by Inclusion Complexation. Journal of American Chemical Society, 128, 3703-3708. http://dx.doi.org/10.1021/ja056775v

[7] Zheng, H., Rao, Y., Yin, Y., Xiong, X., Xu, P. and Lu, B. (2011) Preparation, Characterization, and in Vitro Drug Release Behavior of 6-Mercaptopurine-carboxymethyl Chitosan. Carbohydrate Polymer, 83, 1952-1958. http://dx.doi.org/10.1016/j.carbpol.2010.10.069

[8] Gong, X., Yin, Y., Huang, Z., Lu, B., Xu, P., Zheng, H., Xiong, F., Xu, H., Xiong, X. and Gu, X. (2012) Preparation, Characterization and in Vitro Release Study of a Glutathione-Dependent Polymeric Prodrug Cis-3-(9H-purin-6-ylthio)acrylic acid-graft-carboxymethyl chitosan. International Journal of Pharmaceutics, 436, 240-247. http://dx.doi.org/10.1016/j.ijpharm.2012.06.043

[9] Chang, D., Lei, J., Cui, H., Lu, N., Sun, Y., Zhang, X., Gao, C., Zheng, H. and Yin, Y. (2012) Disulfide Cross-Linked Nanospheres from Sodium Alginate Derivative for Inflammatory Bowel Disease: Preparation, Characterization, and in Vitro Drug Release Behavior. Carbohydrate Polymer, 88, 663-669. http://dx.doi.org/10.1016/j.carbpol.2012.01.020

[10] Gao, C., Liu, T., Dang, Y., Yu, Z., Wang, W., Guo, J., Zhang, X., He, G., Zheng, H., Yin, Y. and Kong, X. (2014) $\mathrm{pH} /$ Redox Responsive Core Cross-Linked Nanoparticles from Thiolated Carboxymethyl Chitosan for in Vitro Release Study of Methotrexate. Carbohydrate Polymer, 111, 964-970. http://dx.doi.org/10.1016/j.carbpol.2014.05.012

[11] Wang, W., Yang, H., Kong, X., Ye, Z., Yin, Y., Zhang, X., He, G., Xu, P. and Zheng, H. (2014) Hydrogen-Bonding Strategy for Constructing pH-Sensitive Core-Shell Micelles with Hydrophilic Polymer as the Shell and Hydrophobic Drug as the Core. RSC Advances, 4, 28499-28503. http://dx.doi.org/10.1039/c4ra03716b

[12] Schafer, F.Q. and Buettner, G.R. (2001) Redox Environment of the Cell as Viewed through the Redox State of the Glutathione Disulfide/Glutathione Couple. Free Radical Biology Medicine, 30, 1191-1212. http://dx.doi.org/10.1039/c4ra03716b 
[13] Zacchigna, M., Cateni, F., Di-Luca, G. and Drioli, S. (2007) A Simple Method for the Preparation of PEG-6-mercaptopurine for Oral Administration. Bioorganic \& Medicinal Chemistry, 17, 6607-6609. http://dx.doi.org/10.1016/j.bmcl.2007.09.064

[14] Chen, Y., Peng, C. and Lu, Y. (2015) Responsiveness and Release Characteristic of Semi-IPN Hydrogels Consisting of Nano-Sized Clay Crosslinked Poly(Dimethylaminoethyl Methacrylate) and Linear Carboxymethyl Chitosan. Journal of Nanoscience and Nanotechnology, 15, 164-171. http://dx.doi.org/10.1166/jnn.2015.8768

[15] Gerweck, L.E. and Seetharaman, K. (1996) Cellular pH Gradient in Tumor versus Normal Tissue: Potential Exploitation for Treatment of Cancer. Cancer Research, 56, 1194-1198.

[16] Doerr, I.L., Wempen, I., Clarke, D.A. and Fox, J.J. (1961) Thiation of Nucleosides. III. Oxidation of 6-Mercaptopurines. Journal of Organic Chemistry, 26, 3401-3409. http://dx.doi.org/10.1021/jo01067a093

[17] Rajendiran, N., Mohandoss, T. and Sankaranarayanan, R.K. (2014) Nanostructure Formed by Cyclodextrin Covered Procainamide through Supramolecular Self-Assembly-Spectral and Molecular Modeling Study. Spectrochimica Acta Part A: Molecular and Biomolecular Spectroscopy, 136, 875-883. http://dx.doi.org/10.1016/j.saa.2014.09.108

[18] Arti, M., Manisha, S. and Deepak, S. (2011) Investigation of the Binding of Roxatidine Acetate Hydrochloride with Cyclomaltoheptaose ( $\beta$-Cyclodextrin) Using IR and NMR Spectroscopy. Carbohydrate Research, 346, 1809-1813. http://dx.doi.org/10.1016/j.carres.2011.07.003

[19] Warayuth, S., Onanong, N., Pattarapond, G., Somsak, S., Issara, S., Apinan, S., Satit, P. and Uracha, R. (2012) Water-Soluble $\beta$-Cyclodextrin Grafted with Chitosan and Its Inclusion Complex as a Mucoadhesive Eugenol Carrier. Carbohydrate Polymer, 89, 623-631. http://dx.doi.org/10.1016/j.carbpol.2012.03.060

[20] Yuan, P., Chengde, L., Zhongxing, Z., Kerh, L., Jianhai, C. and Jun, L. (2011) Chitosan-Graft-(PEI- $\beta$-Cyclodextrin) Copolymers and Their Supramolecular PEGylation for DNA and siRNA Delivery. Biomaterials, 32, 8328-8341. http://dx.doi.org/10.1016/j.biomaterials.2011.07.038 